\title{
Zayıf Elektrik Balıklarında Duyumotor Kontrolcü ve Hareket Dinamiklerinin Alt Uzay Tabanlı Sistem Tanılaması
}

\author{
İsmail Uyan $\mathrm{k}^{1 *}$ \\ 1*Hacettepe Üniversitesi, Mühendislik Fakültesi, Elektrik ve Elektronik Mühendisliği Bölümü, Ankara, Türkiye, (ORCID: 0000-0002-3535-5616), \\ uyanik@ee.hacette.edu.tr
}

(İlk Geliş Tarihi 16 Mayıs 2021 ve Kabul Tarihi 5 Ağustos 2021)

(DOI: $10.31590 /$ ejosat.937828)

ATIF/REFERENCE: Uyanık, İ. (2021). Zayıf Elektrik Balıklarında Duyumotor Kontrolcü ve Hareket Dinamiklerinin Alt Uzay Tabanlı Sistem Tanılaması. Avrupa Bilim ve Teknoloji Dergisi, (25), 623-628.

$\ddot{O} \mathbf{z}$

Canlılarda duyusal ve motor sistemleri arasında muhteşem bir dinamik kapalı döngü etkileşim vardır. Davranışsal bir görev sırasında merkezi sinir sistemi çevreden gelen duyusal sinyalleri algılar ve belirli motor sinyalleri üretir. Ortaya çıkan bu motor sinyalleri ise iskelet ve kas sistemlerini tetikleyerek hareketi oluştururlar. Bu kapalı döngü sistemde merkezi sinir sistemi bir nevi 'kontrolcü', iskelet ve kas sistemleri ise bir nevi 'plant' olarak düşünülebilir. Bu çalışmanın amacı davranışsal görevler esnasında merkezi sinir sistemi tarafından uygulanan duyumotor kontrolcü ve gerçekleştirilen hareket dinamiklerinin sistem tanılamasını yapmaktır. Bu amaçla zayıf elektrik balıklarının sığınak takibi davranışı sırasında toplanmış bir veri kümesinden faydalanılarak bu balıkların takip davranışı esnasında uygulakdıkları kontrolcü ve yüzme dinamikleri elde edilmiştir. Ortaya çıkan sistem modelini kontrol teorisi alanına taşıyabilmek adına alt uzay tabanlı sistem tanılama kullanılmıştır. Böylece hem duyumotor kontrolcü hem de hareket dinamikleri için durum uzay matrisleri elde edilmiştir.

\section{Subspace-Based System Identification of Sensorimotor Control and Locomotor Dynamics of Weakly Electric Fish}

\begin{abstract}
There is a fascinating dynamic closed-loop interaction between the sensory and motor systems in animals. During behavioral tasks, the central nervous system perceives the sensory signals from the environment and generates associated motor commands. Subsequently, these motor signals stimulate the musculoskeletal system to initiate movement. In this closed-loop interaction, the central nervous system plays the role of a 'controller', while the musculoskeletal system becomes the 'plant'. The goal of this paper is to identify the sensorimotor controller and the locomotor dynamics adopted by animals during behavioral task control. To achieve this, we identified the sensorimotor controller and the locomotor dynamics of weakly electric fish during refuge tracking behavior. We used subspace identification to convey the estimated model to the control theory domain. Thus, we obtained a state-space representation both for the sensorimotor controller and the locomotor dynamics of the fish.
\end{abstract}

Keywords: Sensorimotor control, System identification, Weakly electric fish, Subspace identification.

\footnotetext{
* Sorumlu Yazar: uyanik@ee.hacettepe.edu.tr
} 


\section{Giriş}

Canlıların davranışsal görevler sırasındaki performansları duyumotor kontrolcüleri ve görev tabanlı sistem dinamiklerinin karşılıklı etkileşimi ile belirlenmektedir. Burada duyumotor kontrolcü duyusal sistemleri ve bu sistemlerden gelen sinyalleri işleyerek hareket komutlarını oluşturan motor sinirlerini içermektedir (Cowan \& Fortune, 2007; Kiemel vd., 2011). Sistem dinamikleri ise hareketi gerçekleştirebilmek amacıyla çevreyle etkileşim kuran iskelet ve kas sistemlerinden meydana gelmektedir (Hedrick \& Robinson, 2010; Maladen vd., 2009). Amacımız canlıların serbest ve kısıtlanmamış davranışları esnasında uyguladıkları duyumotor kontrolcülerin ve gerçekleştirdikleri sistem dinamiklerinin alt uzay tabanlı sistem tanılamasinı yapabilmektir.

Canlılarda duyumotor kontrolcü ve hareket dinamiklerinin birbirinden ayrıştırılarak sistem tanılamasının yapılabilmesi oldukça güçtür. Bunun en önemli nedenlerinden birisi duyumotor kontrolcü ile hareket dinamiklerinin kapalı döngü bir kontrol sistemi içerisinde çalışıyor olmasıdır (Şekil 1A). Davranışsal canlı deneylerinde her ne kadar bir uyaran girdi sinyaline (Şekil 1A'daki $r(t)$ ) karşılık canlının davranışsal cevabı (Şekil 1A'daki $y(t)$ ) ölçülebilse de kontrolcü çıktısının (Şekil 1A'daki $u(t)$ ) bir ölçümü yapılmadan duyumotor kontrolcü ve hareket dinamiklerinin birbirinden bağımsız olarak sistem tanılamasının yapılabilmesi mümkün değildir.

Bir başka önemli problem ise biyolojik sistemlerde duyumotor kontrolcü ve hareket sistemi arasındaki ayırım noktasının net bir şekilde tanımlanamamasıdır. $\mathrm{Bu}$ bağlamda literatürde elektromiyogram (EMG), elektroensefalogram (EEG) ve fonksiyonel manyetik rezonans görüntüleme (fMRI) verileri sıklıkla duyumotor kontrolcü çıktısının bir yakınsaması olarak kullanılmaktadır (van der Kooij \& Peterka, 2011; Fifer vd., 2013). Ancak bu sinyallerin kullanımıla ilgili temel problemlerden birisi birbiriyle doğrusal olmayan şekillerde etkileşim gösteren farklı kas ve sinir gruplarının koordinasyonunun anlaşılmasını gerektirmesidir (Ting \& Macpherson, 2005). Bu durum duyumotor kontrolcü ve hareket dinamiklerinin kestirilmesinde kullanılacak sistem tanılama sürecini oldukça zorlaştırmaktadır.

Bu çalışmada Eigenmannia virescens türünden zayıf elektrik balıklarının sığınak takibi davranışı sırasında elde edilmiş kinematik verileri kullanılarak balığın benimsediği duyumotor kontrolcü yapısının ve gerçekleştirdiği hareket dinamiklerinin veri güdümlü sistem tanılaması yapılacaktır (Şekil 1B). Bu balıklar doğal sığınma iç güdüleri nedeniyle çevrelerinde bulunan ağaç kovuğu ve kayalıklar gibi alanların içine girerek saklanmayı tercih ederler. Bununla birlikte eşsiz hareket kabiliyetleri sayesinde gerektiğinde ileri ve geri yüzerek içlerinde saklandıkları sığınak alanların hareketini hassas bir şekilde takip edebilirler (Cowan \& Fortune, 2007; Uyanık vd., 2019). Bu amaçla evrimsel süreçte geliştirdikleri ve vücutlarının tüm alt yüzeyini kapsayan anal yüzgeçlerinden faydalanırlar (Sefati vd., 2013; Uyanık vd., 2020a). Bu balıklar vücutları boyunca uzanan anal yüzgeçlerinin iki ucundan birbirine doğru hareket eden dalgalar oluşturarak tek eksende ileri ve geri itki kuvveti uygulayabilirler (Şekil 1C). Bu özellikleri sayesinde Eigenmannia virescens birçok diğer balık türünden farklı olarak tek eksende ileri ve geri yüzebilir. Böylece tek eksende ileri geri hareket eden bir sığınağın hareketlerini hassas bir şekilde takip edebilirler (Sefati vd., 2013; Uyanık vd., 2020a). Balıkların serbest bir şekilde tek eksende gerçekleştirdikleri bu takip davranışı sistem tanılama tekniklerinin uygulanması açısından büyük önem taşımaktadır.

Daha önceki çalışmalarımızda bu balıkların anal yüzgeçlerinde meydana getirdikleri ve karşılıklı hareket eden dalgaların kesiştikleri noktanın ('düğüm' noktası) duyumotor kontrolcü çıktısının bir yakınsaması olarak kullanılabileceğini göstermiştik (Uyanık vd., 2020a). Bu bağlamda farklı frekanslardaki sığınak hareketlerine karşılık, balığın anal yüzgeçlerinde meydana gelen düğüm noktasının ve konumunun takibini içeren kapsamlı bir veri kümesi yayınlanmıştır (Uyanık vd., 2020b). Daha önceki çalışmamızda bu veri kümesi kullanılarak balığın kapalı döngü takip davranışının, $G(s)$, ve hareket dinamiklerinin, $P(s)$, frekans cevapları ve parametrik transfer fonksiyonları kestirilmiştir. Ancak duyumotor kontrolcü yapısı teorik hesaplamaya dayalı olarak $G(s)$ ve $P(s)$ değerleri üzerinden elde edilmiştir. $\mathrm{Bu}$ durum duyumotor kontrolcü kestirimlerinin, $C(s)$, balık dinamiklerine aşırı hassasiyet göstermesine neden olmaktadır. Doğru bir duyumotor kontrolcü kestirimi ancak duyumotor kontrol sisteminin girdisi olan duyusal hata sinyali, $e(t)$, ve duyumotor kontrol sistemi çıktısının bir yakınsaması olan düğüm noktası sinyali, $u(t)$, kullanılarak mümkün olabilecektir.

$\mathrm{Bu}$ çalışmada öncelikle veri güdümlü sistem tanılama tekniklerinden yararlanarak balıkların sığınak takibi davranışı sırasında uyguladıkları duyumotor kontrolcü ve hareket dinamiklerinin alt uzay tabanlı sistem tanılamasını yapacağız. Literatürdeki tekniklerden farklı olarak alt uzay tabanlı sistem tanılama bize düşük dereceli durum uzay gösterimlerinin elde edilebilmesini sağlayacaktır. Duyumotor kontrolcü ve hareket dinamiklerinin durum uzay gösterimlerinin elde edilebilmesi, biyolojik kontrol sistemlerinde incelenecek problemleri kontrol teorisi düzlemine taşıyarak kontrol teorisi literatüründe var olan analiz ve yöntemlerin uygulanabilmesinin önünü açacaktır. Ayrıca, özellikle hareket dinamikleri için elde ettiğimiz sonuçlar alt uzay tabanlı sistem tanılama tekniklerinin farklı parametrik modeller ile karşılaştırıldığında oldukça iyi sonuçlar verdiğini de göstermektedir.
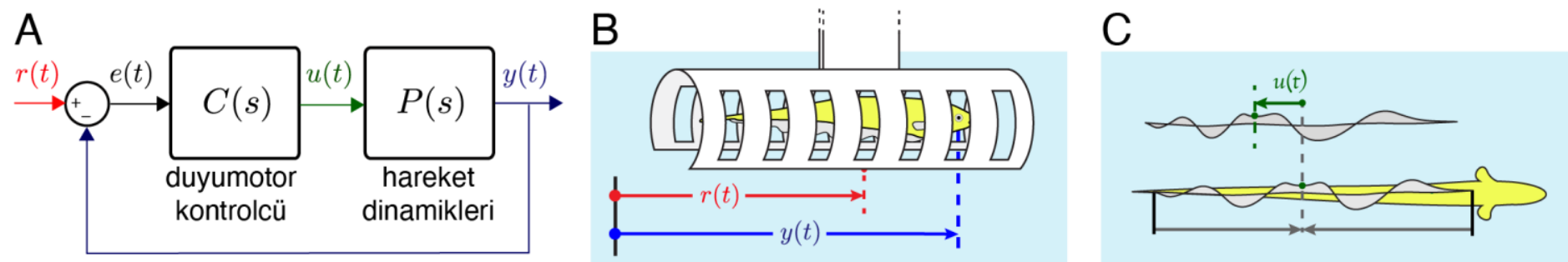

Şekil 1. (A) Eigenmannia virescens balığı için sığınak takibi davranışının öngörülen kapalı döngü geri beslemeli kontrol modeli. (B) Balığın sığınak takibi davranışı esnasındaki hareketlerinin bir canlandırması. (C) Balığın anal yüzgecini kullanarak düğüm noktası konumunu kontrol etmesi ve ileri/geri yönde itki uygulaması 


\section{Materyal ve Metot}

\subsection{Veri Kümesi}

$\mathrm{Bu}$ çalışmada daha önce yazarlar tarafindan toplanmış ve açık kaynak olarak paylaşılmış bir veri kümesinden yararlanılmıştır (Uyanık vd., 2020b). Bu veri kümesinin konusu olan tüm deneysel çalışmalar Johns Hopkins Üniversitesi Hayvan Deneyleri Etik Kurulu tarafından onaylanmıştır.

Deneylerde Eigenmannia virescens türünden üç zayıf elektrik balığının sığınak takibi davranışı sırasındaki davranışsal cevapları incelenmiştir. Balıklar deney öncesinde yaklaşı $27^{\circ} \mathrm{C}$ sicaklıkta ve $50-200 \mu S$ iletkenlikte su içerisinde barındırılmıştır. Her balık ortama alışabilmeleri amacıyla en az 1 gün öncesinden deney akvaryumuna taşınmıştır.

Deney akvaryumu içerisinde balıkların içerisinde saklanabilmesi amacıyla $15 \mathrm{~cm}$ uzunluğunda ve $\sim 5 \mathrm{~cm}$ çapında PVC borudan yapılmış bir sı ğınak yer almaktadır. Bu sı̆̆ınağın alt kısmı görüntü alınabilmesi amaciyla kesilmiş ve yan duvarlarında küçük pencereler açılmıştır (Şekil 1B). Deneyler sırasında bu sığınak bir adım motoru aracılığıyla tek eksende ileri/geri hareket ettirilebilmektedir. Bu hareketlere karş1lık balığın gerçekleştirdiği sı̆̆ınak takibi davranışı $1280 \times 1024$ çözünürlükte bir kamera ile $30 \mathrm{fps}$ 'de kaydedilmiştir. Kaydedilen görüntüler daha sonra şablon eşleştirme (template matching) tabanlı bir görüntü işleme yazılımı kullanılarak analiz edilmiş böylece zamana bağlı sığınak ve balık hareketleri elde edilmiştir.

Sı̆̆ınak hareketleri $0.1 \mathrm{~cm}$ genliğinde ve $0.55,0.95$ ve $2.05 \mathrm{~Hz}$ frekanslarında sinüzoidal sinyallerden meydana gelmektedir. Sinyal genliği balığın anal yüzgecinde birbirlerine doğru hareket eden dalgalar oluşturmak suretiyle sığınak takibi davranışını gerçekleştireceği şekilde belirlenmiştir. Aynı şekilde frekanslar da balığın sığınak takibi davranışını doğrusal olarak gerçekleştirebildiği bir aralıktan seçilmiştir (Roth vd., 2011). Her frekans için 10-13 tekrar yapılmıştır. $\mathrm{Bu}$ tekrarlar sistem tanılama aşamasında deneyler arası değişkenliğin gözlemlenebilmesine fayda sağlayabileceği gibi ortalamaları alınması durumunda balığın zamandan bağımsız cevabının bir yakınsamasının elde edilmesine olanak sağlayacaktır.

\subsection{Alt Uzay Tabanlı Sistem Tanılama}

$\mathrm{Bu}$ çalışmada alt uzay tabanlı sistem tanılama tekniklerinden faydalanarak zayıf elektrik balıklarının duyumotor kontrolcü ve hareket dinamiklerinin durum-uzay matrislerinin kestirimini yapacağız. Bu bağlamda giriş-çıkış verilerinden yararlanarak bu alt sistemler için aşağıdaki formda tek giriş tek çıkışlı bir sistem yaklaşımı elde edilecektir:

$$
\begin{aligned}
& \dot{\bar{x}}(t)=\bar{A} \bar{x}(t)+\bar{B} u(t) \\
& \bar{y}(t)=\bar{C} \bar{x}(t)+\bar{D} \bar{u}(t)
\end{aligned}
$$

Burada $\overline{\mathrm{u}}(t) \in \mathbb{R}, \overline{\mathrm{y}}(t) \in \mathbb{R}, \overline{\mathrm{x}}(t) \in \mathbb{R}^{n}, \overline{\mathrm{A}} \in \mathbb{R}^{n x n}, \overline{\mathrm{B}} \in \mathbb{R}^{n}$, $\overline{\mathrm{C}} \in \mathbb{R}^{1 x n}$ ve $\overline{\mathrm{D}} \in \mathbb{R}$. Bu çalışmada literatürde de sıklıkla kullanılan ve alternatiflerine göre ön plana çıkan başarım özellikleri nedeniyle CVA (canonical variate analysis) algoritması tercih edilmiştir (Favoreel vd., 1999). Bu algoritmanın çalışma prensipleriyle ilgili detaylar (Larimore, 1990)'te bulunmaktadır. Ancak çalışmamızın bütünlüğü ve uygulanan giriş sinyallerinin niteliğine özgü bir anlatım bakımından kullanılan algoritma kısaca özetlenmektedir.
Denklem (1)'de gösterilen sistem öncelikle bilinear (Tustin) dönüşüm ve verinin örnekleme frekansı kullanılarak ayrık zamanlı bir forma getirilir:

$$
\begin{aligned}
x[k+1] & =A x[k]+B u[k] \\
y[k] & =C x[k]+D u[k]
\end{aligned}
$$

Frekans düzlemine geçildiğinde bu denklem aşağıdaki formu almaktadir:

$$
\begin{aligned}
e^{j \omega} X(\omega) & =A X(\omega)+B U(\omega) \\
Y(\omega) & =C X(\omega)+D U(\omega)
\end{aligned}
$$

Çalışmamızda kullanılan verilerde uyaran sinyal olarak sabit frekanslı sinüzoidal sinyaller kullanılmıştır. Frekans düzleminde bu sinyaller negatif ve pozitif frekans değerlerinde birer impuls (dürtü) olarak gözlenmektedir. Zaman düzlemindeki gerçek değerli sinyaller frekans düzleminde karmaşık eşlenik yapıda olacağı için çalışmamızda pozitif frekanslardaki impuls değerleri kullanılacaktr. $\mathrm{Bu}$ bağlamda zaman düzlemindeki giriş sinyali $u[k]=e^{j \omega k}$ olarak düşünüldüğünde, frekans düzlemindeki karşılığı şu şekilde yazılabilir:

$$
U(\omega)=\left[\begin{array}{lllllll}
0 & \cdots & 0 & 1 & 0 & \cdots & 0
\end{array}\right]^{T} .
$$

$\mathrm{Bu}$ durumda (3) numaralı denklem aşağıdaki formda yazılabilir:

$$
\begin{aligned}
e^{j \omega} X(\omega) & =A X(\omega)+B \\
G\left(e^{j \omega}\right) & =C X(\omega)+D
\end{aligned}
$$

Burada $G\left(e^{j \omega}\right)$ sistemin impuls cevabı olarak düşünülebilir. Üstteki denklem durum değişimlerini, alttaki denklem ise çıkış sinyalini ifade etmektedir. Bu noktada çıkış sinyali yinelemeli olarak $e^{j \omega}$ ile çarpıldığında her tekrarda $e^{j \omega} X(\omega)$ değeri durum değişim denkleminden yerine konularak iki denklem istendiği kadar birleştirilebilir. Bu işlem $q$ kez tekrarlandığında aşağıdaki Hankel veri matrisi denklemi elde edilir:

$$
\begin{aligned}
& \underbrace{\left[\begin{array}{c}
G\left(e^{j \omega}\right) \\
G\left(e^{j \omega}\right) e^{j \omega} \\
\vdots \\
G\left(e^{j \omega}\right) e^{j(q-1) \omega}
\end{array}\right]}_{G_{\omega}}=\underbrace{\left[\begin{array}{c}
C \\
C A \\
\vdots \\
C A^{q-1}
\end{array}\right]}_{Q} X(\omega) \\
& +\underbrace{\left[\begin{array}{cccc}
D & 0 & \cdots & 0 \\
C B & D & 0 & \vdots \\
\vdots & \ddots & \ddots & 0 \\
C A^{q-2} B & C A^{q-3} B & \cdots & D
\end{array}\right]}_{\Gamma} \underbrace{\left[\begin{array}{c}
I \\
e^{j \omega} I \\
\vdots \\
e^{j(q-1) \omega} I
\end{array}\right]}_{U_{\omega}}
\end{aligned}
$$

Frekans düzleminde çalışmanın en önemli avantajlarından birisi olarak farklı frekanslarda elde edilen veriler Hankel matrisleri denkleminin yapısını değiştirmeden sadece $G_{\omega}, X(\omega)$, ve $U_{\omega}$ matrislerine her frekans için yeni sütun ekleyerek birleştirilebilir. Birden fazla frekanstaki deney verilerini içeren yeni yapı şu şekilde gösterilebilir:

$$
\boldsymbol{G}=Q \boldsymbol{X}+\Gamma \boldsymbol{U}
$$

$\mathrm{Bu}$ denklemde $\boldsymbol{U}$ ve $\boldsymbol{G}$ matrisleri ölçülebilen giriş ve çıkış sinyalleri kümelerine karşılık gelmektedir. $\mathrm{Bu}$ denklemin giriş matrisine dik olan bir alt uzay kümesine, $\mathbf{U}^{\perp}$, izdüşümü alındığında

$$
\boldsymbol{G} \mathbf{U}^{\perp}=Q \boldsymbol{X} \mathbf{U}^{\perp}+\overbrace{\Gamma \boldsymbol{U} \mathbf{U}^{\perp}}^{0}
$$

elde edilir. Giriş matrisinin kendine dik bir alt uzaya düşümü sıfırdır. Eşitliğin sol tarafında kalan kısım ölçülebilen giriş ve 
çıkış sinyallerinden meydana gelmektedir. Sağ tarafta kalan $Q X \mathbf{U}^{\perp}$ kısmı ise gözlenebilirlik matrisi $Q$ ile durum değişiminin giriş sinyaline dik bir alt uzayına iz düşümünden meydana gelmektedir. $\mathrm{Bu}$ durumda eşitliğin sol tarafina tekil değer ayrıştırması (SVD) uygulayarak sistemin gözlenebilirlik matrisi için bir kestirim elde edilebilir. Örneğin,

$$
\boldsymbol{G} \mathbf{U}^{\perp}=\left[\begin{array}{ll}
\widehat{U}_{n} & \widehat{U}_{0}
\end{array}\right]\left[\begin{array}{cc}
\widehat{\Sigma}_{n} & 0 \\
0 & \widehat{\Sigma}_{0}
\end{array}\right]\left[\begin{array}{c}
\widehat{V}_{n}^{T} \\
\widehat{V}_{0}^{T}
\end{array}\right]
$$

olarak ayrıştırıldığında gözlenebilirlik matrisi aşağıdaki şekilde seçilebilir:

$$
Q=\left[\begin{array}{c}
C \\
C A \\
\vdots \\
C A^{q-1}
\end{array}\right]=\widehat{U}_{n} \widehat{\Sigma}_{n}^{1 / 2}
$$

Bu eşitlikten $C$ matrisi doğrudan $A$ matrisi ise en küçük kareler metodu ile kolaylıkla hesaplanabilir. $A$ ve $C$ matrisleri elde edildiğinde benzer bir şekilde $B$ ve D matrisleri de en küçük kareler yöntemiyle (5) numaralı denklem kullanılarak elde edilebilir. Bu çözümdeki iki önemli nokta denklem (6) ve (7)'de yapılan iki kritik seçimdir. Öncelikle denklem (6)'da elde edilecek sistemin boyutuna karar verilmektedir. $\mathrm{Bu}$ sayı tekil değerlerin yapısına göre büyüklük sıralamasında bir kopmaya göre yapılabilir. Alternatif olarak Akaike ya da Bayesian bilgi kriterlerine göre de elde edilebilmektedir. Biz bu çalışmada Akaike ve Bayesian bilgi değerlerinin boyuta göre değişimine karar vererek boyut belirlemesi yapacağız. İkinci olarak denklem (7)'de $Q$ matrisi için bir değer ataması yapılmaktadır. Bu noktada farklı seçimler farklı $C$ ve $A$ matrislerinin kestirimine yol açacaktır. Ancak bu durum elde edilecek sistemin kestirim performansını etkilemeyecek sadece farklı bir benzerlik dönüşümünden geçmiş farklı durum değişkenlerinin ortaya çıkmasına neden olacaktır. Alt uzay tabanlı sistem tanılama yöntemlerinin bu noktada önemli bir dezavantajı sistemin orjinal durum değişkenlerinin kestiriminin mümkün olmamasıdır. Ancak bu durum bu çalışmada olduğu gibi birçok biyolojik sistem uygulaması için bir önem arz etmemektedir. Kaldı ki zaten nöral kontrol sistemleri için matematiksel modelleme teknikleriyle dahi durum değişkenlerinin belirlenmesi mümkün olmamaktadır.

\section{Araştırma Sonuçları ve Tartışma}

\subsection{Hareket Dinamiklerinin Sistem Tanılaması}

$\mathrm{Bu}$ bölümde amacımız balık ve düğüm noktasının konum bilgilerini kullanarak balığın hareket dinamiklerine ait durumuzay matrislerinin kestirimini yapmaktır. Şekil 2 sı ğınak $0.95 \mathrm{~Hz}$ frekansında hareket ederken elde edilmiş düğüm noktası ve balık pozisyonu grafiklerini göstermektedir. Referans bir sığınak hareketi için 13 farklı deney bölümünden elde edilen düğüm noktası ve balık verileri yarı transparan olarak gösterilmektedir. Ayrıca bu verilerin ortalama değerleri de koyu renkli olarak gösterilmektedir. Şekil 1(A) ile de ilişkilendirilerek düşünülürse bu sistemde sığınak, düğüm noktası ve balık pozisyonu arasında doğrusal bir ilişki olduğu kabullenmesi yapılabilir, zira referans sığınak hareketleri sonucu ortaya çıkan düğüm noktası ve balık hareketleri sığınak ile aynı frekansta ancak farklı büyüklük ve faz açısında karşımıza çıkmaktadır. Her ne kadar düğüm noktası hareketleri bazı yüksek frekanslı harmonikler içerse de gerek daha önceki çalışmalar (Sefati vd.,
2013) gerekse güncel analizlerimiz bize düğüm noktasının majör frekansının sığınak frekansında olduğunu göstermektedir.
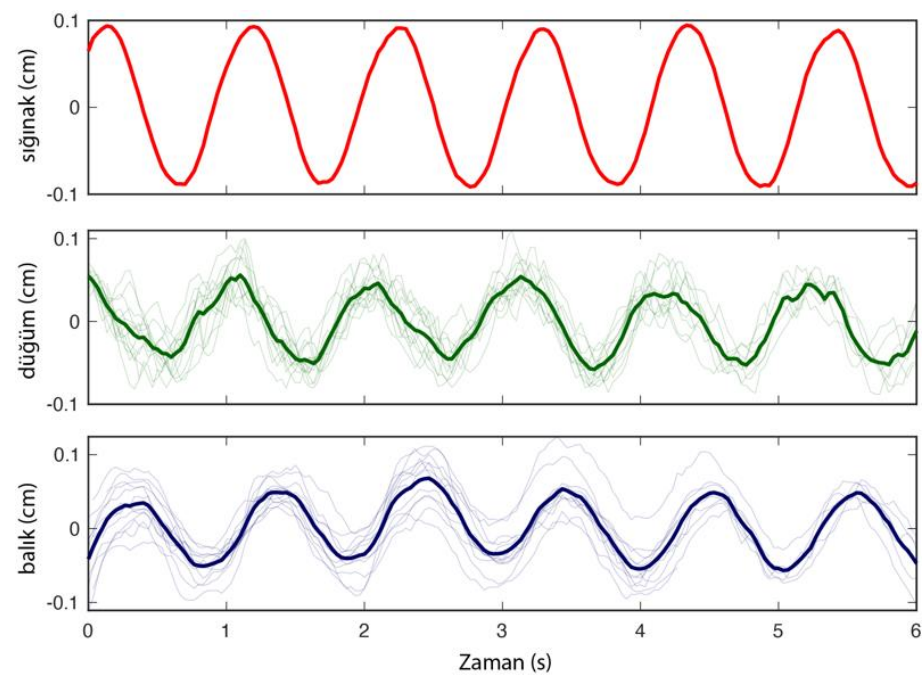

Şekil 2. Birinci balı̆̆ın sı̆̆ınak $0.95 \mathrm{~Hz}^{\prime}$ de hareket ederken gerçekleştirdiği dügüm noktası hareketlerinin ve konumunun değişimi. Farklı tekrarların sonuçları yarı transparan olarak, ortalama sonuçlar ise koyu renkle gösterilmiştir.

Balığın hareket dinamiklerinin sistem tanılaması amacıyla düğüm noktası hareketleri giriş balık hareketleri ise çıkış sinyali olacaktır. Böylece uygulanacak alt-uzay tabanlı sistem tanılama algoritması bize balığın hareket dinamikleri için durum-uzay matrislerinin bir kestirimini sağlayacaktır. Bölüm 2.2'de anlatıldığı üzere farklı frekanslarda gerçekleştirilen deneylerden elde edilen sinyaller ile önce giriş ve çıkış veri matrisleri oluşturulmuştur. Elde edilecek durum-uzay gösteriminin boyutlarının belirlenebilmesi amacıyla ise hem Akaike hem de Bayesian bilgi kriterleri (AIC ve BIC) verileri incelenmiştir. Şekil 3 durum değişkenleri sayısı 1 ile 10 arasında değişirken AIC ve BIC değişimlerini göstermektedir. Bu grafikte minimum AIC ve BIC değerlerini veren değişken sayısı (her ikisi için dört) bize sistemin seçilebilecek maksimum değişken sayısını belirtmektedir. Şekil 3 'te elde edilen sonuçlar bize üç durum değişkeninden sonra AIC ve BIC değerlerindeki değişimin çok az olduğunu göstermektedir. Bu nedenle alt uzay sistem tanılama işlemi için durum değişkeni sayısı 3 olarak belirlenmiştir.

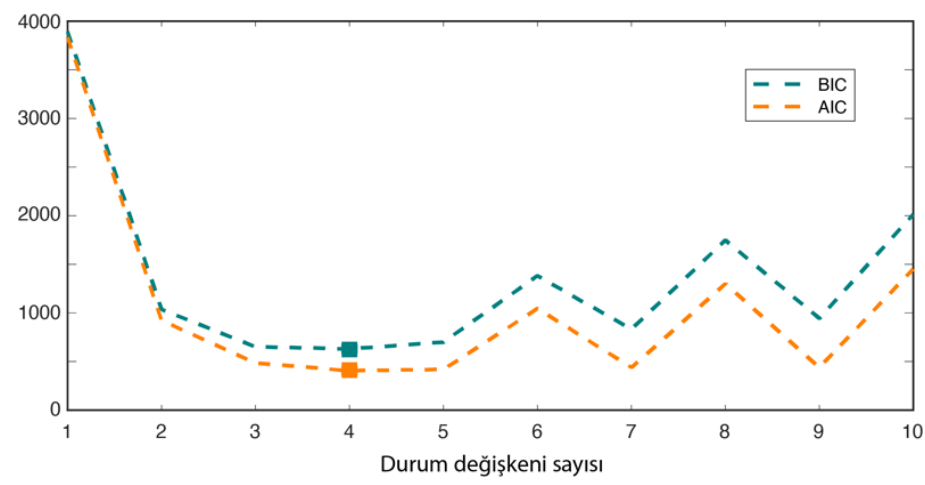

Şekil 3. Hareket dinamikleri için AIC ve BIC değerlerinin durum değişken sayısına göre değişimi

Balığın hareket dinamikleri için denklem (1) formatında elde edilen sistemin, $P_{1}(s)$, durum uzay matrisleri aşağıdaki gibidir:

$$
A=\left[\begin{array}{ccc}
0 & 1 & 0 \\
0 & 0 & 1 \\
-15.56 & -17.31 & -5.89
\end{array}\right] \quad \begin{array}{lll}
B & =\left[\begin{array}{lll}
0.62 & 22.34 & -94.56
\end{array}\right]^{T} \\
C & =\left[\begin{array}{lll}
1 & 0 & 0
\end{array}\right]
\end{array}
$$


Elde edilen sistemin başarımını değerlendirebilmek adına literatürde balıkların hareket dinamiklerini ifade edebilmek amacıyla kullanılmış (Sefati vd., 2013; Uyanik vd., 2020a) iki parametrik sistemi modeli için de sistem tanılama yapılmıştır:

$$
\begin{gathered}
P_{2}(s)=\frac{4.04}{0.1 s^{2}+s} \\
P_{3}(s)=\frac{3.97 s+3.46}{s^{2}+0.23 s+2.02}
\end{gathered}
$$

$\mathrm{Bu}$ üç model için tüm veriler üzerindeki kök ortalama kare hata (RMSE) değerleri aşağıdaki gibidir:

$$
\begin{aligned}
& P_{1}(s): 0.0179 \\
& P_{2}(s): 0.0487 \\
& P_{3}(s): 0.0318
\end{aligned}
$$

Ayrıca bu üç modelin örnek bir düğüm noktası sinyali için balık hareketlerini kestirim performansı Şekil 4'te verilmiştir. Tüm bu verilerden görüleceği üzere alt uzay sistem tanılama modeli literatürdeki örneklere nazaran oldukça başarılı kestirim sonuçları sunmaktadır. Ayrıca durum uzay gösteriminin elde edilmesi birçok kontrol teorisi yönteminin kestirilen sistem üzerinde uygulanabilmesine olanak sağlayacaktır.

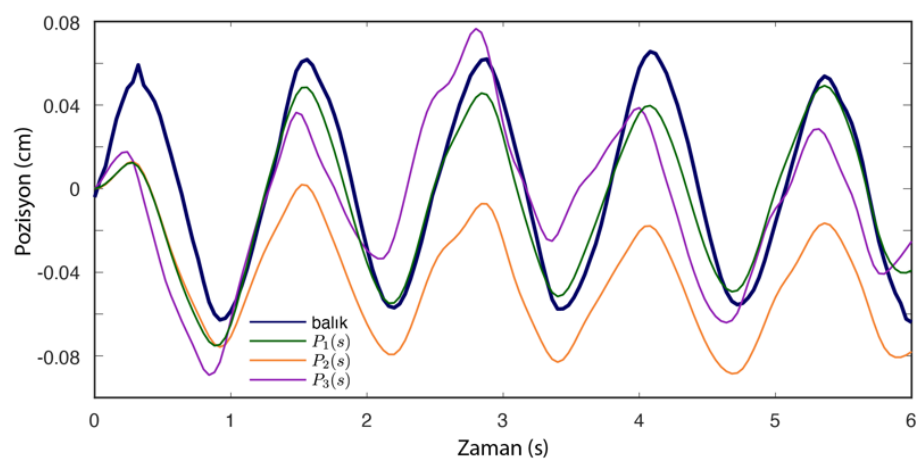

Şekil 4. Farklı sistem tanılama modellerinin örnek bir balık hareketi üzerinde kestirim performanslarının karşılaştırılması

\subsection{Duyumotor Kontrolcü Dinamiklerinin Sistem Tanılaması}

$\mathrm{Bu}$ bölümde balıkların sı̆̆ınak takibi davranışı sırasında uyguladıkları duyumotor kontrolcünün sistem tanılaması yapılacaktır. Sonuçları sunmadan önce bir noktanın tekrar ve net olarak ifade edilmesi oldukça önemlidir. $\mathrm{Bu}$ çalışmada gerçekleştirilen veri güdümlü sistem tanılama spesifik olarak balığın sığınak takibi davranışı sırasında uyguladığı duyumotor kontrolcüyü ortaya çıkaracaktır. Nitekim bu kontrol algoritması farklı davranışlar için dramatik değişiklikler gösterebilir.

Bu kısımda da yine bölüm 2.2'de detayları verilen veri güdümlü alt uzay sistem tanılama yöntemi kullanılmıştır. Ancak bu bölümde giriş sinyali olarak Şekil 1(A)'da gösterilen ve duyumotor kontrolcü bloğuna giren duyusal fark, $e(t):=r(t)-$ $y(t)$, sinyali kullanılacaktır. Tanımdan da anlaşılacağı üzere duyusal fark sinyali sı ğınak hareketi ile balığın kendi hareketleri arasındaki farka karşılık gelmektedir. Zira balık sığınak içinde takip hareketini gerçekleştirirken sığınak ve kendisinin global pozisyonlarını değil aradaki farkı algılayabilmektedir (Cowan \& Fortune, 2007).

Öncelikle sistem boyutunun belirlenebilmesi adına farklı durum değişkeni sayıları için AIC ve BIC değişim grafiği elde edilmiştir. Şekil 5'te görüleceği üzere hem AIC hem de BIC için durum değişkeni sayısının 2-7 arasındaki değişimi en düşük değerleri vermektedir. $\mathrm{Bu}$ bağlamda yine en sade çözümü kullanmak adına sistem boyutu 2 olarak belirlenmiştir. Burada önemli olan bir nokta aynı kapalı döngü kontrol sistemi içerisinde çalışan duyumotor kontrolcü ve hareket dinamikleri için farklı durum değişkeni sayısı kullanılmış olmasıdır. Bu durum teorik olarak hiçbir sorun addetmemektedir.

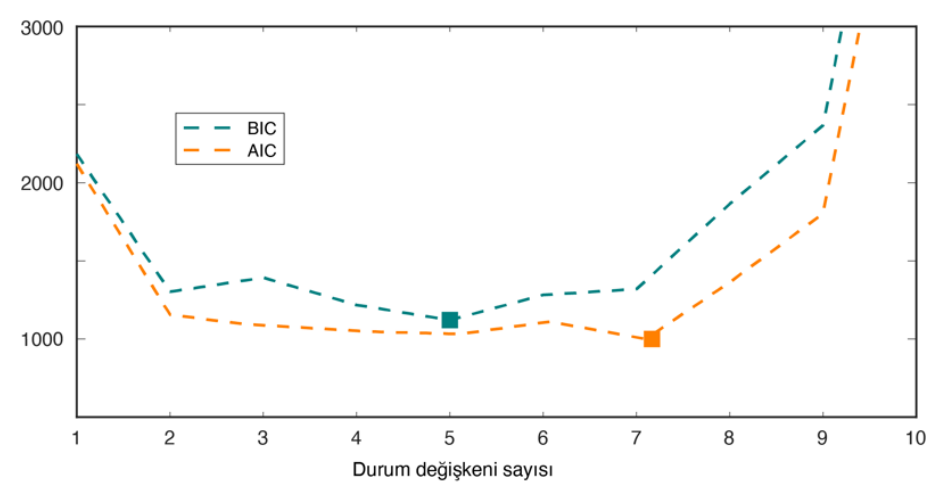

Şekil 5. Duyumotor kontrolcü için AIC ve BIC değerlerinin durum değişken sayısına göre değişimi

Durum değişkeni sayısı 2 için duyumotor kontrolcünün denklem (1) formatında elde edilen durum uzay gösterimi aşağıdaki gibidir:

$$
\left.A=\left[\begin{array}{cc}
-8.86 & -33.79 \\
1 & 0
\end{array}\right] \quad \begin{array}{l}
B=\left[\begin{array}{ll}
1 & 0
\end{array}\right]^{T} \\
C=\left[\begin{array}{ll}
2.19 & -9.48
\end{array}\right], D=[0.27
\end{array}\right]
$$

Elde edilen durum uzay gösteriminin düğüm noktası üzerindeki kestirim performansı Şekil 6'da örnek bir sinyal üzerinde gösterilmektedir. Göründüğü üzere duyusal fark sinyalinden düğüm noktasının hareketine tanımlanan duyumotor kontrolcü davranışı ikinci derece bir durum uzay gösterimi ile başarılı bir şekilde ifade edilebilmektedir.

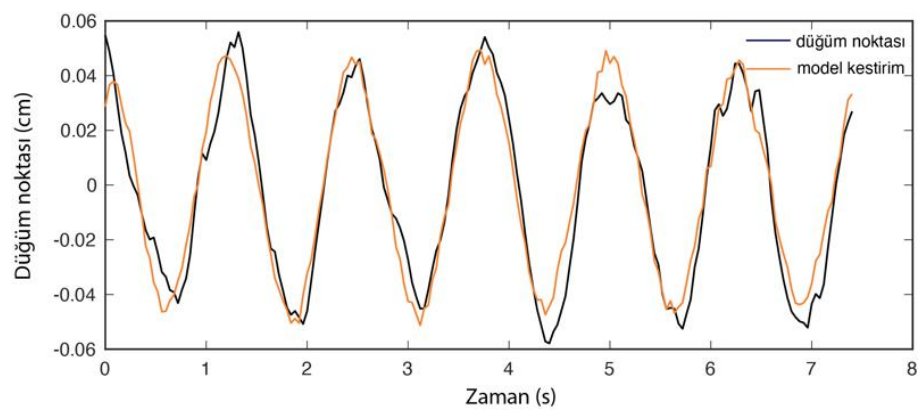

Şekil 6. Tanılanan sistem modelinin gerçek balık verisi üzerinde düğ̈̈m noktası kestirimi

Literatürde zayıf elektrik balıklarında sığınak takibi davranışı sırasındaki duyumotor kontrolcü yapısıyla ilgili olarak karşılaştırma sağlanacak bir örnek bulunamamıştır. Ancak daha önceki çalışmalar bize bu balıklarda takip davranışı sırasında uygulanan duyumotor kontrolcülerin yüksek frekans geçiren filtre karakteristikleri gösterdiklerini söylemektedir (Uyanık vd., 2020a). Bu nedenle biz de alt uzay sistem tanilama yöntemiyle elde ettiğimiz durum uzay gösteriminin frekans cevabını inceleyerek literatürde yer alan bu bulguları test ettik.

Şekil 7 tanılanan sistem modelinin uyaran frekans bandındaki frekans cevabını göstermektedir. Görüldüğü üzere sığınak takibi davranışı sırasında uygulanan duyumotor kontrolcü yüksek frekans geçiren filtre karakteristiklerine sahiptir. Bu da alt uzay sistem tanılama yöntemiyle elde edilen sonuçların literatürle eşleştiğini göstermektedir. 

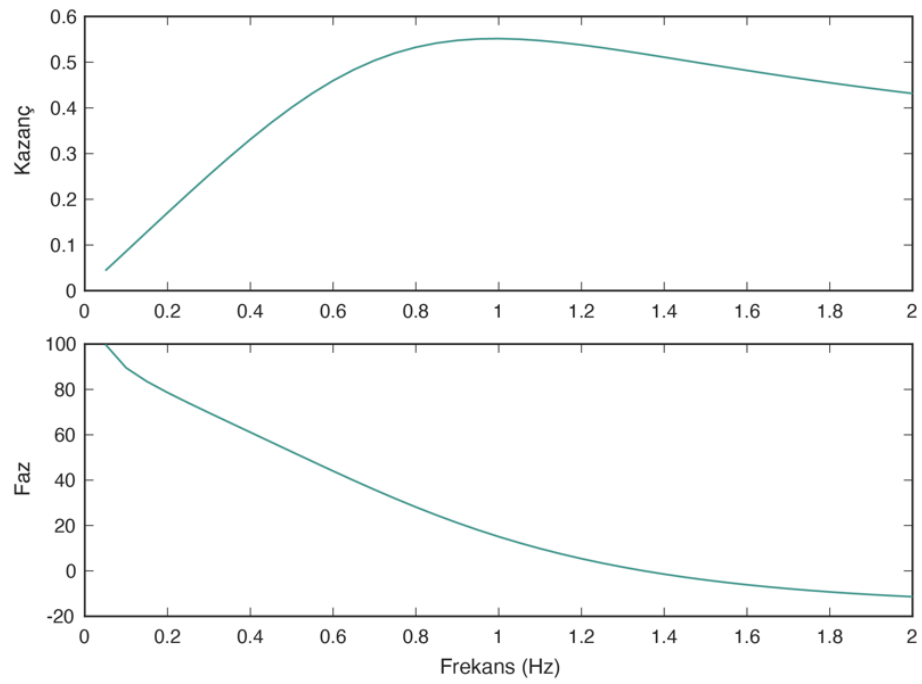

Şekil 7. Tanılanan modelin frekans cevabı

\section{Sonuç}

$\mathrm{Bu}$ çalışmada zayıf elektrik balıklarının sı̆̆ınak takibi davranışı sırasında uyguladıkları duyumotor kontrolcü ve hareket dinamiklerinin sistem tanılaması yapılmıştır. $\mathrm{Bu}$ bağlamda daha önce bu balıklarla toplanmış bir veri kümesinden faydalanılmıştır. Elde edilen veriler üzerinde alt uzay tabanlı sistem tanılama teknikleri kullanılarak hem duyumotor kontrolcü hem de hareket dinamikleri için durum uzay matrislerinin kestirimi yapılmıştır. Elde edilen sonuçlar kestirilen sistem modellerinin veriyi başarılı bir şekilde ifade ettiğini ortaya koymaktadır.

Ortaya çıkan önemli sonuçlardan birisi aslında hem duyumotor kontrolcü hem de hareket dinamiklerinin oldukça düşük boyutlu doğrusal sistemlerle ifade edilebiliyor olmasıdır. Duyumotor kontrol yapısı her ne kadar karmaşık ve doğrusal olmayan bir sistem olsa da spesifik bir davranış esnasında gerçeklenen kontrolcü yapısının oldukça basit sistem modelleriyle ifade edilebildiği gösterilmiştir.

$\mathrm{Bu}$ çalışmada tartışılması gereken en önemli noktalardan birisi ise kapalı döngü bir kontrol sistemi içerisindeki alt sistem bloklarının giriş_çıkış sinyalleri yardımıyla açık döngü bir biçimde tanılanmış olmasıdır. $\mathrm{Bu}$ tip sistem tanılama problemlerinde ortaya çıkabilecek en önemli handikaplardan birisi giriş_çıkış sinyalleri ile kestirilecek modelin hedeflenen alt bloğu mu yoksa bu bloğun kapalı döngü kontrol sistemindeki tamamlayıcı kısmını mı ifade ettiğinin bilinememesidir. $\mathrm{Bu}$ çalışmada elde edilen modeller literatürde daha önce ilgili birimler için elde edilen sonuçlarla karşılaştırılarak hedeflenen alt blokların sistem tanılamasının yapıldığı doğrulanmıştır. Bu problemin kalıcı çözümü ortak giriş çıkış sistem tanılama yöntemleriyle mümkündür. Ancak ne yazık ki bu çalışmada kullanılan veri kümesi bu yöntemlerin uygulanması için yeterli içeriğe sahip değildir.

\section{Teşekkür}

$\mathrm{Bu}$ çalışma TÜBİTAK tarafından 120E198 numaralı proje kapsamında desteklenmektedir.

\section{Kaynakça}

Cowan, N. J., \& Fortune, E. S. (2007). The critical role of locomotion mechanics in decoding sensory systems. Journal of neuroscience, 27(5), 1123-1128.

Favoreel, W., Van Huffel, S., De Moor, B., Sima, V., \& Verhaegen, M. (1999). Comparative study between three subspace identification algorithms. In European Control Conference (ECC), pp. 821-826. IEEE.

Fifer, M. S. vd. (2013). Simultaneous neural control of simple reaching and grasping with the modular prosthetic limb using intracranial EEG. IEEE transactions on neural systems and rehabilitation engineering, 22(3), 695-705.

Hedrick, T. L., \& Robinson, A. K. (2010). Within-wingbeat damping: dynamics of continuous free-flight yaw turns in Manduca sexta. Biology letters, 6(3), 422-425.

Kiemel, T., Zhang, Y., \& Jeka, J. J. (2011). Identification of neural feedback for upright stance in humans: stabilization rather than sway minimization. Journal of neuroscience, 31(42), 15144-15153.

Larimore, W. E. (1990). Canonical variate analysis in identification, filtering, and adaptive control. In 29th IEEE Conference on Decision and control (pp. 596-604).

Maladen, R. D., Ding, Y., Li, C., \& Goldman, D. I. (2009). Undulatory swimming in sand: subsurface locomotion of the sandfish lizard. Science, 325(5938), 314-318.

Roth, E., Zhuang, K., Stamper, S. A., Fortune, E. S., \& Cowan, N. J. (2011). Stimulus predictability mediates a switch in locomotor smooth pursuit performance for Eigenmannia virescens. Journal of experimental biology, 214(7), 11701180 .

Sefati, S., Neveln, I. D., Roth, E., Mitchell, T. R., Snyder, J. B., MacIver, M. A., ... \& Cowan, N. J. (2013). Mutually opposing forces during locomotion can eliminate the tradeoff between maneuverability and stability. Proceedings of the national academy of sciences, 110(47), 18798-18803.

Ting, L. H., \& Macpherson, J. M. (2005). A limited set of muscle synergies for force control during a postural task. Journal of neurophysiology, 93(1), 609-613.

Uyanik, I., Stamper, S. A., Cowan, N. J., \& Fortune, E. S. (2019). Sensory cues modulate smooth pursuit and active sensing movements. Frontiers in behavioral neuroscience, 13,59

Uyanik, I., Sefati, S., Stamper, S. A., Cho, K. A., Ankarali, M. M., Fortune, E. S., \& Cowan, N. J. (2020a). Variability in locomotor dynamics reveals the critical role of feedback in task control. eLife, 9, e51219.

Uyanik, I., Sefati, S., Stamper, S. A., Cho, K. A., Ankarali, M. M., Fortune, E. S., \& Cowan, N. J. (2020b). Data associated with publication "Variability in locomotor dynamics reveals the critical role of feedback in task control". Johns Hopkins University Data Archive, doi:10.7281/T1/UDTJPD, V1.

Van Der Kooij, H., \& Peterka, R. J. (2011). Non-linear stimulusresponse behavior of the human stance control system is predicted by optimization of a system with sensory and motor noise. Journal of computational neuroscience, 30(3), 759-778. 